In this observation, the fluorescence confocal microimaging of the distal lung displayed characteristic PAP globular structures that appeared highly fluorescent in vivo. We reviewed 173 alveolar areas explored with confocal fluorescence endomicroscopy from 24 smoking non-PAP subjects, including nine patients with various interstitial lung diseases (ILD) (sarcoidosis $n=1$; respiratory bronchiolitis-interstitial lung disease $n=4$; asbestosis $n=1$; systemic sclerosis $n=1$; histiocytosis $n=1$; and cryptogenic organising pneumonia $n=1$ ) and 15 healthy volunteers. None of the alveolar areas explored in the non-PAP ILD patients and healthy volunteers displayed the fluorescent globular material that was observed in our PAP patient. Therefore, these endomicroscopic characteristics appear strongly suggestive of the diagnosis of PAP during the bronchoscopy procedure. In a previous study [3], the authors were able to demonstrate that, in smokers, the strong fluorescence of the alveolar macrophages was related to the retention of tobacco tar in the alveolar fluid and macrophages. Tobacco tar is highly fluorescent at $488 \mathrm{~nm}$ excitation [10]. From this observation, it cannot be excluded that the visualisation of the globular fluorescent substance is related to the presence of the tobacco tar within the lipoproteinaceous PAP material. Therefore, the alveolar FCFM findings in nonsmoking PAP patients may differ from those described in our observation. However, because the majority of patients with primary PAP are active smokers [5, 11], this may represent a small limitation for the procedure, which should be further explored.

In conclusion, fluorescence bronchoalveoscopy is a minimally invasive and safe technique that may provide specific in vivo microimaging of PAP in real-time in smoking patients.

\author{
M. Salaün*,\#, F. Roussel ${ }^{\top}$, P-A. Hauss*, S. Lachkar* and \\ L. Thiberville*,\# \\ *Clinique Pneumologique, Rouen University Hospital, "Dept \\ of Pathology and Cytology, Rouen University Hospital, and \\ \#QuantIF Laboratory LITIS EA 4108, Faculty of Medicine and \\ Pharmacy, Rouen University, Rouen, France.
}

Correspondence: L. Thiberville, Clinique Pneumologique, Hôpital Charles Nicolle, CHU de Rouen, 1 rue de Germont, 76031 Rouen Cedex, France. E-mail: Luc.Thiberville@univ-rouen.fr

Statement of Interest: A statement of interest for L. Thiberville can be found at www.erj.ersjournals.com/misc/statements.dtl

\section{REFERENCES}

1 Thiberville L, Moreno-Swirc S, Vercauteren T, et al. In vivo imaging of the bronchial wall microstructure using fibered confocal fluorescence microscopy. Am J Respir Crit Care Med 2007; 175: 22-31.

2 Thiberville L, Salaun M, Lachkar S, et al. Confocal fluorescence endomicroscopy of the human airways. Proc Am Thorac Soc 2009; 6 : 444-449.

3 Thiberville L, Salaun M, Lachkar S, et al. Human in vivo fluorescence microimaging of the alveolar ducts and sacs during bronchoscopy. Eur Respir J 2009; 33: 974-985.

4 Maygarden SJ, Iacocca MV, Funkhouser WK, et al. Pulmonary alveolar proteinosis: a spectrum of cytologic, histochemical, and ultrastructural findings in bronchoalveolar lavage fluid. Diagn Cytopathol 2001; 24: 389-395.

5 Seymour JF, Presneill JJ. Pulmonary alveolar proteinosis: progress in the first 44 years. Am J Respir Crit Care Med 2002; 166: 215-235.

6 Trapnell BC, Whitsett JA, Nakata K. Pulmonary alveolar proteinosis. N Engl J Med 2003; 349: 2527-2539.

7 Holbert JM, Costello P, Li W, et al. CT features of pulmonary alveolar proteinosis. AJR Am J Roentgenol 2001; 176: 1287-1294.

8 Frazier AA, Franks TJ, Cooke EO, et al. From the archives of the AFIP: pulmonary alveolar proteinosis. Radiographics 2008; 28: 883-899.

9 Kitamura T, Uchida K, Tanaka N, et al. Serological diagnosis of idiopathic pulmonary alveolar proteinosis. Am J Respir Crit Care Med 2000; 162: 658-662.

10 Skold CM, Hed J, Eklund A. Smoking cessation rapidly reduces cell recovery in bronchoalveolar lavage fluid, while alveolar macrophage fluorescence remains high. Chest 1992; 101: 989-995.

11 Inoue $\mathrm{Y}$, Trapnell BC, Tazawa R, et al. Characteristics of a large cohort of patients with autoimmune pulmonary alveolar proteinosis in Japan. Am J Respir Crit Care Med 2008; 177: 752-762.

\title{
Undiagnosed coeliac disease in patients with emphysema: a fortuitous association?
}

\section{To the Editors:}

Chronic obstructive pulmonary disease (COPD) is characterised by progressive and poorly reversible airflow obstruction due to small airway disease and emphysema. Cigarette smoking is the major cause of COPD, but the disease also occurs in nonsmokers. In nonsmokers, environmental factors (e.g. second-hand smoking and inhalation of toxic gas), genetic factors (e.g. the rare $\alpha_{1}$-antitrypsin deficiency) and infectious factors (e.g. HIV infection) have been implicated in the pathogenesis of the disease. We report on two cases of
COPD with emphysema in nonsmokers with long-standing undiagnosed coeliac disease.

A 71-yr-old female was referred to our hospital (Hôpital Cochin, Assistance Publique-Hôpitaux de Paris, Paris, France) for dyspnoea and cough, which had evolved over 5 yrs. She had suffered from alternating diarrhoea and constipation for many years, ascribed to functional bowel disease. She had never been exposed to inhaled toxics and had never smoked. Examination revealed a body mass index (BMI) of $18 \mathrm{~kg} \cdot \mathrm{m}^{-2}$ and a chest computed tomography (CT) image revealed 
pulmonary distension and emphysema (fig. 1). Spirometry revealed severe airflow limitation (table 1 ). Serum $\alpha_{1}$-antitrypsin was normal. Treatment with long-acting bronchodilators was initiated. After $7 \mathrm{yrs}$ of follow-up, the patient complained of progressive weight loss (BMI $15 \mathrm{~kg} \cdot \mathrm{m}^{-2}$ ) and increased diarrhoea. Vitamin D deficiency was found, suggesting malabsorption. Anti-endomysium, anti-gliadin and antitransglutaminase antibodies were detected. Gastroscopy revealed a macroscopic aspect of pavimental mucosa and duodenal biopsies showed subtotal villous atrophy with increased numbers of intraepithelial lymphocytes, confirming coeliac disease. Diarrhoea and weight loss improved markedly on a gluten-free diet, but no significant changes in lung function were observed.

A 59-yr-old female was referred to our hospital (Hôpital Cochin, Assistance Publique-Hôpitaux de Paris) after two episodes of acute bronchitis and weight loss of $5 \mathrm{~kg}$. She had never smoked and had never been exposed to inhaled toxics. She also complained of asthenia, chronic pain of the wrists and fingers, and chronic itching for several years. She signalled that she had always had soft saddles. Examination showed mild malnutrition (BMI $18 \mathrm{~kg} \cdot \mathrm{m}^{-2}$ ). Laboratory tests showed chronic microcytic anaemia and severe iron deficiency. A chest CT image showed centrilobular and bullous emphysema, which predominated in lower lobes (fig. 1). Spirometry showed mild airflow limitation and plethysmography revealed pulmonary hyperinflation. Serum $\alpha_{1}$-antitrypsin was normal. The patient declined bronchoscopy and no bronchoalveolar lavage was performed. Gastroscopy was performed to explore iron deficiency and showed a typical pavimental aspect of duodenal mucosa. Biopsies revealed total villous atrophy with lymphocytic infiltrate of the mucosa. Antibodies against gliadin, endomysium and transglutaminase were all positive. Further exploration showed marked vitamin D deficiency and severe osteoporosis. Coeliac disease was treated with a glutenfree diet, which resulted in a rapid improvement in itching, joint pain and diarrhoea. No significant changes in pulmonary abnormalities occurred.

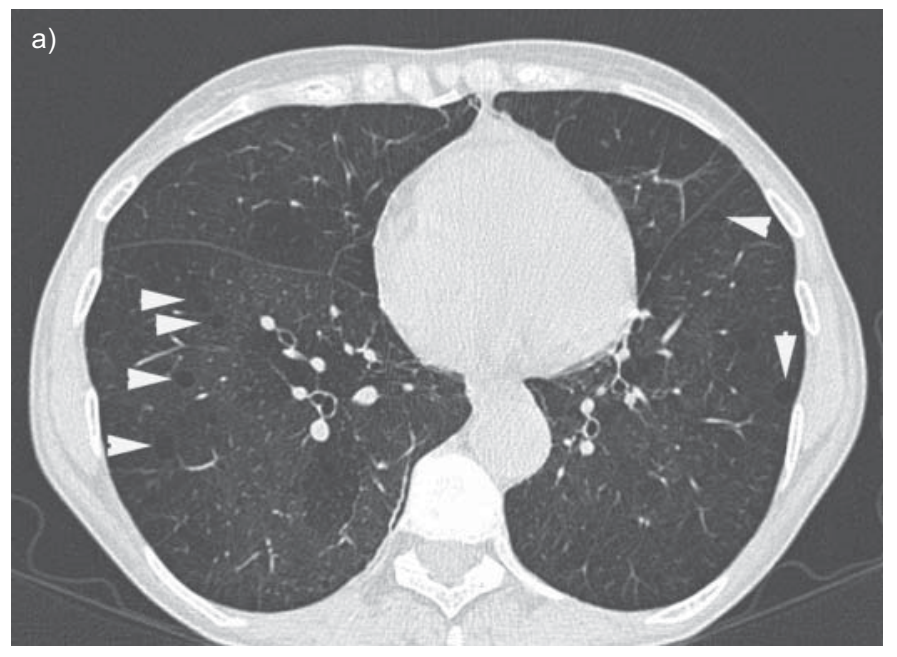

Coeliac disease was originally considered a rare malabsorption syndrome of childhood, but is now recognised as a common condition that may be diagnosed at any age. Coeliac disease may affect many organ systems including the neurological system, skin and liver [1]. Previous reports have suggested links between coeliac disease and several pulmonary manifestations, including diffuse pulmonary nodules, interstitial fibrosis, lymphocytic bronchoalveolitis and pulmonary haemosiderosis [2].

An association between emphysema and coeliac disease has been previously suggested [3-5]. In a study of a case of malabsorption, intestinal mucosal atrophy and ulceration, cirrhosis, and emphysema, the authors suggested that emphysema was unrelated to coeliac disease because the patient was a heavy smoker [3]. In another report, coeliac disease was associated with emphysema, which was ascribed to $\alpha_{1^{-}}$ antitrypsin deficiency [5]. In a pathological study of lung specimens obtained in 14 patients (10 current or ex-smokers) with coeliac disease complaining of respiratory symptoms (e.g. dyspnoea and/or cough), EDWARDS et al. [4] described airflow obstruction in seven patients and peribronchiolar fibrosis in 12 patients. However, because lung function was normal in the four nonsmokers and because most bronchiolar abnormalities were found in current or ex-smokers, the authors suggested that these findings were unrelated to coeliac disease [4].

Our cases differ from previous reports in that both patients were lifelong nonsmokers and had no $\alpha_{1}$-antitrypsin deficiency. Although we cannot rule out that the observed associations between coeliac disease and emphysema occurred by chance, our report is consistent with the findings of TARLO et al. [6] who reported mild airflow obstruction in 18 subjects with biopsy-proven coeliac disease compared with 18 control subjects matched for age, sex and smoking.

Coeliac disease is a unique autoimmune disorder because the environmental precipitant (gluten) is known [1]. Recently, evidence has emerged that auto-immunity may be involved in the pathogenesis of alveolar destruction characteristic of

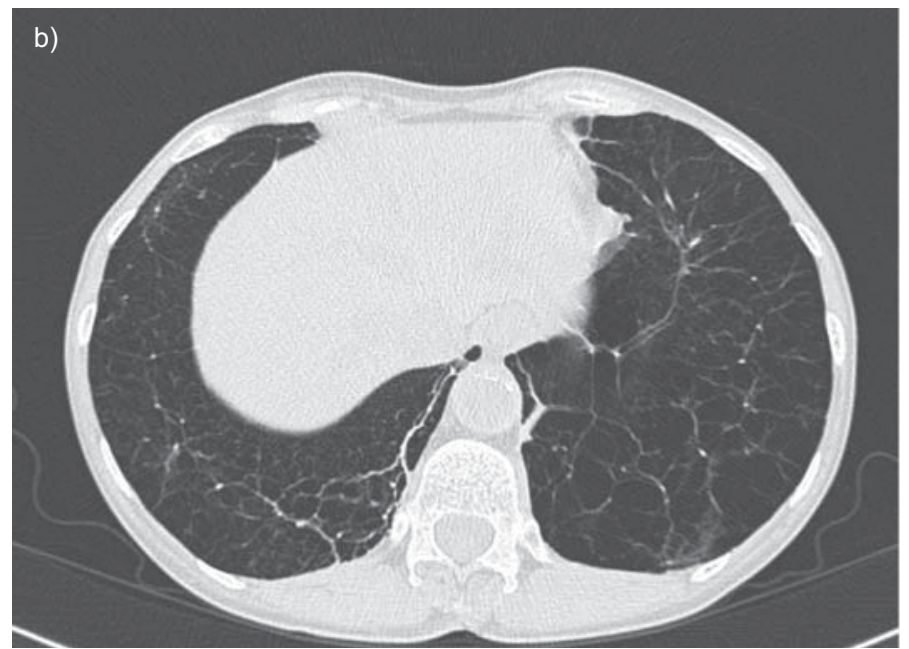

FIGURE 1. a) High-resolution computed tomography images obtained in patient 2 reveals focal areas of low attenuation (arrowheads) within a homogeneous background of lung parenchyma, characterising centrilobular emphysema. b) Bullous emphysema in the same patient. 


\begin{tabular}{|c|c|c|}
\hline Age at diagnosis of emphysema yr & 71 & 59 \\
\hline BMI $\mathbf{k g} \cdot \mathbf{m}^{-2}$ & 18 & 18 \\
\hline Smoking & Never & Never \\
\hline Inhaled toxics & None & None \\
\hline $\mathrm{FEV}_{1} / \mathrm{FVC}^{\#}$ & 31.9 & 45.8 \\
\hline TLC L (\% pred) & $4.448(94)$ & $6.800(133)$ \\
\hline RV L (\% pred) & $1.910(91)$ & $3.190(165)$ \\
\hline $\mathrm{Pa}, \mathrm{O}_{2} \mathrm{mmHg}$ & 68 & 79 \\
\hline $\mathrm{Pa}, \mathrm{CO}_{2} \mathrm{mmHg}$ & 36 & 32 \\
\hline Duodenal biopsy & Subtotal villous atrophy & Total villous atrophy \\
\hline IgG anti-gliadin $\mathrm{U} \cdot \mathrm{mL}^{-1}$ & 23 & 62 \\
\hline IgA anti-gliadin $\mathrm{U} \cdot \mathrm{mL}^{-1}$ & $>150$ & 114 \\
\hline IgG anti-transglutaminase & + & 20 \\
\hline IgA anti-transglutaminase & + & $>120$ \\
\hline Haemoglobin $\mathbf{g} \cdot \mathrm{dL}^{-1}$ & 13.2 & 10.8 \\
\hline Mean corpuscular volume $\mu \mathrm{m}^{3}$ & 93 & 74 \\
\hline Ferritin $\mathrm{ng} \cdot \mathrm{mL}^{-1}$ & 154 & 3 \\
\hline 25 hydroxy vitamin $D_{3} \mathrm{ng} \cdot \mathrm{mL}^{-1}$ & 15 & 12 \\
\hline
\end{tabular}

BMI: body mass index; FEV1: forced expiratory volume in $1 \mathrm{~s} ; \%$ pred: \% predicted; FVC: forced vital capacity; TLC: total lung capacity; RV: residual volume; $P$ a $\mathrm{O}_{2}$ : arterial oxygen tension; $\mathrm{Pa}_{1} \mathrm{CO}_{2}$ : arterial carbon dioxide tension; $\mathrm{CT}$; computed tomography; Ig; immunoglobulin. ${ }^{\#}$ : results are presented as post-bronchodilator data.

emphysema [7]. Because autoimmune diseases are often associated, it is possible that both diseases coexist and/or that auto-antibodies share antigen specificity. Another possible explanation is related to long-standing malnutrition. Severe malnutrition caused by starvation during World War II or by anorexia nervosa has been associated with the development of emphysema [8]. Furthermore, vitamin D deficiency, which was present in our patients, has been linked with abnormal lung function [9]. We suggest that long-standing malabsorption occurring in patients with coeliac disease may induce lung inflammation and emphysema. In support of the latter hypothesis, BRIGHTLING et al. [2] reported CD4+ lymphocytic bronchoalveolitis in a 68-yr-old female with a 1-yr history of dry cough, which improved markedly after several months on a gluten-free diet. We could not demonstrate such findings in our patients because patient 1 had severe bronchial obstruction and patient 2 declined bronchoscopy.

In summary, we suggest that coeliac disease diagnosis should be considered in patients with emphysema, especially when classical risk factors for emphysema (e.g. smoking) are absent. Further research is also warranted to examine the prevalence of emphysema in patients with coeliac disease. If confirmed, the association between emphysema and coeliac disease may provide new insights into the pathogenesis of emphysema and coeliac disease.
M. de Menthon*, D.J. Dusser", L. Guillevin* and P.R. Burgel ${ }^{\#}$ Depts of *Internal Medicine, and "Respiratory Medicine, Hôpital Cochin, Assistance Publique-Hôpitaux de Paris, Université Paris Descartes, Paris, France.

Correspondence: P.R. Burgel, Service de Pneumologie, Hôpital Cochin, Assistance Publique Hôpitaux de Paris, 27 rue du Faubourg St Jacques, 75679 Paris, Cedex 14, France. E-mail: pierre-regis.burgel@cch.aphp.fr

Statement of Interest: None declared.

\section{REFERENCES}

1 Green PH, Cellier C. Celiac disease. N Engl J Med 2007; 357: 1731-1743.

2 Brightling CE, Symon FA, Birring SS, et al. A case of cough, lymphocytic bronchoalveolitis and coeliac disease with improvement following a gluten free diet. Thorax 2002; 57: 91-92.

3 A case of malabsorption, intestinal mucosal atrophy and ulceration, cirrhosis, and emphysema. BMJ 1970; 3: 207-212.

4 Edwards C, Williams A, Asquith P. Bronchopulmonary disease in coeliac patients. J Clin Pathol 1985; 38: 361-367.

5 Greenwald AJ, Johnson DS, Oskvig RM, et al. $\alpha$-1-Antitrypsin deficiency, emphysema, cirrhosis, and intestinal mucosal atrophy. JAMA 1975; 231: 273-276. 
6 Tarlo SM, Broder I, Prokipchuk EJ, et al. Association between celiac disease and lung disease. Chest 1981; 80: 715-718.

7 Lee SH, Goswami S, Grudo A, et al. Antielastin autoimmunity in tobacco smoking-induced emphysema. Nat Med 2007; 13: 567-569.

8 Coxson HO, Chan IH, Mayo JR, et al. Early emphysema in patients with anorexia nervosa. Am J Respir Crit Care Med 2004; 170: 748-752.
9 Black PN, Scragg R. Relationship between serum 25-hydroxyvitamin $\mathrm{D}$ and pulmonary function in the third national health and nutrition examination survey. Chest 2005; 128: 3792-3798.

DOI: $10.1183 / 09031936.00020210$ 